\title{
Serebral palsi tanısı ile izlediğimiz çocuklarda kullandığımız ortezler ve fonksiyonel durum ile ilişkisi
}

\author{
The use of orthosis in children with cerebral palsy and the relationship between orthosis \\ and functional status
}

Ayla Çağlıyan Türk

Gönderilme tarihi:28.11.2018

Kabul tarihi:28.12.2018

\begin{abstract}
Özet
Amaç: Polikliniğimize Serebral palsi tanısı ile başvuran hastaların kullanmakta olduğu ortez çeşitlerini belirlemek, SP tipinin ve Kaba Motor Fonksiyonel Sınıflama Sisteminin (KMFSS) ortezleme ile ilişkisini değerlendirmek.

Gereç ve yöntem: SP tanısı olan 2-16 yaş arası hastalar retrospektif olarak incelendi ve ortez kullanımı saptanan 60 hasta çalışmaya dahil edildi. Hastaların yaş, cinsiyet, akraba evliliği öyküsü, konuşma bozukluğu, mental bozukluk, görme bozukluğu, işitme bozukluğu, epilepsi, yutma bozukluğu ve kullandığı ortez kaydedildi. Klinik sınıflama Swedish klasifikasyonuna göre yapıldı. Hastaların kaba motor fonksiyonlarındaki bozukluğun ciddiyetini sınıflandırmak için Kaba Motor Fonksiyon Sınıflandırma Sistemi (KMFSS) kullanıldı.

Bulgular: Hastaların ortalama yaşı 88,05 $\pm 50,44$ ay idi. Olguların'33 ü erkek 27'si kızdı. Hastaların \%96,7'si $(n=58)$ spastik tip, \%3,3'ü $(n=2)$ diskinetik tip SP idi. Spastik tip SP'lerin \%36,7'si diplejik, \%36,7'si tetraplejik, \%20'si hemiplejik, \%3,3'ü monoplejik idi. KMFSS'ye göre yapılan sınıflamada en fazla KMFSS-3 hastası vardı (\% 35). KMFSS-1 olan 7 hasta solid AFO, KMFSS-2 olan 10 hastanın 3'ü GRAFO, 7'si solid AFO kullanıyordu. KMFSS-3 olan 21 hastanın 3 tanesi KAFO, 2'si GRAFO, biri eklemli AFO, 17'si solid AFO kullanıyordu. KMFSS-4 olan 15 hastanın 6'sı KAFO, biri GRAFO, 8'i solid AFO kullanıyordu. KMFSS-5 olan 7 hastanın 3'ü KAFO, 4'ü solid AFO kullanıyordu.

Sonuç: KMFSS 1, 2 ve 3 olan hastalar daha çok AFO ve GRAFO kullanırken KMFSS 4 ve 5 olan hastaların yaklaşık yarısında KAFO kullanımı vardı. KMFSS 4 ve 5 olan çocuklar kendi kendilerine hareketleri sınırlı ve sıklıkla taşındıkları için yürüme amaçlı AFO yerine pozisyonlamaya ve eklem hareket açıklığını korumaya yönelik KAFO kullanımı daha fazladır.
\end{abstract}

Anahtar kelimeler: Serebral palsi, ortez kullanımı.

Çağlıyan Türk A. Serebral palsi tanısı ile izlediğimiz çocuklarda kullandığımız ortezler ve fonksiyonel durum ile ilişkisi. Pam Tıp Derg 2019;12:149-155.

\begin{abstract}
Purpose: To determine the types of orthoses used by patients with cerebral palsy and to evaluate the relationship between Cerebral palsy (CP) type and the Gross Motor Function Classification System (GMFCS) with the orthoses.

Material and methods: Patients aged between 2 and 16 years who were diagnosed with CP were retrospectively evaluated and sixty patients with orthotic use were included in the study. Age, sex, and orthosis were assessed. Clinical classification was based on Swedish classification. The GMFCS was used to classify the severity of impairment in gross motor functions of patients.

Results: The mean age of the patients was $88.05 \pm 50.44$ months. $55 \%$ of the patients were female, $45 \%$ were male. $96.7 \%$ of the patients were spastic CP, $3.3 \%$ were dyskinetic type CP. According to GMFCS, there were at most KMFSS-3 patients (35\%). Seven patients with GMFCS-1 had solid AFO. Three patients with GMFCS-2 had GRAFO and seven patients had solid AFO. Of the twenty-one patients with GMFCS-3, 3 had KAFO, 2 had GRAFO, one had hinged AFO and seventeen had solid AFO. Of the fifteen patients with GMFCS-4, 6 had KAFO, one had GRAFO and 8 had solid AFO. Three patients with GMFCS-5 had KAFO and 4 patients had solid AFO.

Conclusion: The patients with GMFCS 1-2-3 had mostly use AFO and GRAFO, approximately half of patients with GMFCS 4-5 had KAFO. Since the children in GMFCS 4-5 have limited self-movements and are often transported, it is expected that the use of KAFO for positioning rather than walking AFO.
\end{abstract}

Key words: Cerebral palsy, orthosis.

Çağlıyan Türk A. The use of orthosis in children with cerebral palsy and the relationship between orthosis and functional status. Pam Med J 2019;12:149-155. 


\section{Giriş}

Serebral palsi (SP); gelişmekte olan fetal veya infant beyninde oluşan, progresif olmayan bir hasara bağlı olarak gelişen, aktivite limitasyonuna neden olan, hareket ve postür gelişiminin kalıcı bozukluğudur [1].

SP'de spastisite, selektif motor kontrol kaybı ve propriyosepsiyon bozukluğu gibi nöromüsküler problemler yürüme fonksiyonunu tehlikeye atabilir [2]. Yürüme sırasında, SP'li çocukların özürlü olmayan akranlarına oranla daha fazla oksijen gereksinimleri vardır [3].

Verimli ve etkili yürüyüş, SP'li çocuklar için önemli bir tedavi hedefidir çünkü hareketlilik, çocuğun işlevsel bağımsızlığı ve topluma katılımı ile ilişkilidir [4]. Ortez kullanımı, yürüme ve postürü etkileyen bazı durumlar için önemli ve yararlı bir tedavi seçeneğidir ve genellikle SP'li hastalar için oluşturulan rehabilitasyon programının bir parçasını oluşturur [5].

SP'de ortez tedavisi en sık, deformiteleri önlemek ya da eklemleri stabilize ederek destek sağlamak amacıyla kullanılır. Yerçekimi ya da dengesiz kas güçleri sonucunda oluşan fleksible eklem deformiteleri pasif olarak düzeltilebilir ve ortez kullanılarak pozisyonlanabilir. Hızlı büyüme çağında, ortezlerin kullanımı ile kasların uzun süreli gergin tutulmasının, kasların yeterli uzunluğa erişmesi için gerekli stimulusları sağladığı düşünülmektedir. Günde en az altı saat ortez kullanımıyla, kasların uzunlamasına pozisyonda tutulması kontraktür gelişimini önleyebilmektedir [6]. Ortezler ayrıca yürüyüş parametrelerini iyileştirmek ve özellikle spastik SP'de hareket paternlerini normalleştirmek için de kullanılmaktadır [5]. Uygun bir ortez stabiliteyi artırarak daha düşük enerji maliyeti de sağlayabilir [3].

Bir ortez tasarlayabilmek için, kas-iskelet sisteminin normal gelişiminin bilinmesi, tam gelişmemiş kas-iskelet sistemi üzerine etki eden iç ve dış güçlerin anlaşılması, bu kuvvetlerin nasıl değiştirilebileceğinin bilinmesi ve ortezin yararlı/zararlı etkilerinin tanınması anahtar konulardır [7]. Ortez ile ilgili karara varırken, bireyin fonksiyonel durumundaki gelişmelerine göre ortez takibinin yapılmasının gerekliliği göz önünde bulundurulmalıdır [8]. Uygun tedavi planı çocuğun fonksiyonel kapasitesine, aile ve sosyal çevre koşullarına göre yapılmalıdır.
SP'nin tutulum tipi, çocuğun fonksiyonel motor seviyesi, eşlik eden komplikasyonları, spastisite varlığı, pasif ve aktif eklem hareket açıkığı, oturma ve ayakta durma dengesi, selektif motor kontrol, kas gücü, deformite tipi değerlendirilmelidir [9].

Bu çalışmada polikliniğimize Serebral Palsi tanısı ile başvuran hastaların kullanmakta olduğu ortez çeşitleriniN belirlenmesi, SP tipinin ve Kaba Motor Fonksiyonel Sınıflama Sisteminin ortezleme ile ilişkisinin değerlendirilmesi amaçlanmıştır.

\section{Gereç ve Yöntem}

Hitit Üniversitesi Tıp Fakültesi Fiziksel Tıp ve Rehabilitasyon Polikliniğine müracaat eden SP tanısı olan 2-16 yaş arası hastalar retrospektif olarak incelendi ve ortez kullanımı saptanan 60 hasta çalışmaya dahil edildi. Lokal etik kurul onayı alındı. Hastaların yaş, cinsiyet, SP ile ilişkili olabilecek risk faktörleri, akraba evliliği öyküsü, kardeşte hastalık, konuşma bozukluğu, mental bozukluk, görme bozukluğu, işitme bozukluğu, epilepsi, yutma bozukluğu ve kullandığı ortez kaydedildi.

Klinik sınıflama İsveç klasifikasyonuna göre yapıldı [10]. Hastalar; spastik (tetraplejik, diplejik, hemiplejik), diskinetik (atetoid, distonik), ataksik, mikst tip şeklinde gruplandırıld.

Hastaların kaba motor fonksiyonlarındaki bozukluğun ciddiyetini sınıflandırmak için Kaba Motor Fonksiyon Sınıflandırma Sistemi (KMFSS) kullanıldı. KMFSS, SP'li çocukların kaba motor fonksiyonlarını beş seviyede sınıflayan geçerli ve güvenilir standardize bir sistemdir. SP'li çocuklar motor fonksiyonlarda Seviye 1'de en az bağımlı, Seviye 5'te ise en fazla bağımlıdır (Tablo 1) [11].

Hastaların kullanmakta olduğu ortez çeşitleri [solid ayak-ayak bileği ortezi (ankle-footorthosis), (solid AFO)], eklemli ayak-ayak bileği ortezi (eklemli AFO), yer reaksiyonlu ayakayakbileği ortezi (GRAFO), diz-ayak bileği-ayak ortezi [(knee ankle food orthosis), (KAFO)] sorgulandı. Yürümeye yardımcı cihaz kullanımı (yürüteç, tripod, tetrapod, tekerlekli sandalye) not edildi.

İstatistiksel analiz SPSS 21.0 programı kullanılarak yapıldı. Tanımlayıcı istatistiksel metotlar kullanıldı. 
Tablo 1. Kaba motor fonksiyon sınıflandırma sistemi seviye tanımlama

1. Kısıtlama olmaksızın yürür, daha ileri kaba motor becerilerde kısıtlanma

2. Yardımcı cihazsız yürürler, ev dışında ve toplumda yürümede kısıtlanma

3. Mobiliteye yardımcı cihazlarla yürürler, ev dışı ve toplumda yürümede kısıtlanma

4. Kendi kendine hareket sınırlı, çocuklar taşınırlar veya ev dışı ve toplumda enerjili mobilite cihazları kullanır

5. Kendi kendine hareket yardımcı teknoloji kullanımıyla bile ileri derecede sınırlıdır.

\section{Bulgular}

Hastaların ortalama yaşı $88,05 \pm 50,44$ ay idi.

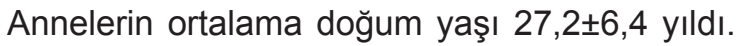
Problemin farkedilme yaşı $8 \pm 9,5$ aydı. Olguların 33'ü erkek 27'si kızdı.

Hastaların \%15'inde (n=9) akraba evliliği öyküsü, \%8,3'ünde (n=5) kardeşte SP tanısı mevcuttu. 34 hastada $(\% 56,7)$ konuşma bozukluğu, 30 hastada (\%50) mental bozukluk saptandı. \%35 ( $n=21)$ hastada görme bozukluğu, $\% 8,3 \quad(n=5)$ hastada işitme bozukluğu, $\% 36,7 \quad(n=22) \quad$ hastada epilepsi, \%33,3 $(n=20)$ hastada yutma bozukluğu saptandı. Hastaların \%51,7'sine $(n=31)$ botilinium toksini uygulanmıştı. Onsekiz hastada (\%30) geçirilmiş cerrahi öyküsü mevcuttu.

Hastaların \%96,7'si (n=58) spastik tip, $\% 3,3$ 'ü $(n=2)$ diskinetik tip SP idi. Spastik tip SP'lerin \%36,7'si $(n=22)$ diplejik, \%36,7'si $(n=22)$ tetraplejik, \%20'si $(n=12)$ hemiplejik, \%3,3'ü (n=2) monoplejik idi (Tablo 2).

KMFSS'ye göre yapılan sınıflamada \%35 $(n=21)$ ile en fazla KMFSS Seviye 3 düzeyinde hasta olduğu belirlendi. Hastaların KMFSS dağılımı Tablo 3'de görülmektedir.
Hastaların \%68,3'ü ( $n=41$ ) solid AFO, \%1,7'si $(n=1)$ eklemli AFO, \%10'u $(n=6)$ GRAFO, \%20 'si (n=12) KAFO kullanıyordu. \%33,3'ü $(n=20)$ yürümeye yardımcı cihaz kullanıyordu (Tablo 4).

Yirmi iki diplejik hastanın 17'si solid AFO, biri eklemli AFO, üçü GRAFO ve bir tanesi KAFO kullanıyordu. Yirmiiki tetraplejik hastanın 9'u KAFO, 11'i solid AFO, bir tanesi GRAFO kullanıyordu. Yirmi hemiplejik SP'nin 2'si KAFO, 2'si GRAFO, 16'sı solid AFO kullanıyordu. İki monoplejik hasta solid AFO kullanıyordu. Diskinetik SP'li hastaların ikisi de solid AFO kullanmaktaydı (Tablo 5).

KMFSS Seviye 1 olan 7 hasta solid AFO, KMFSS Seviye 2 olan 10 hastanın 3'ü GRAFO, 7'si solid AFO kullanıyordu. KMFSS Seviye 3 olan 21 hastanın 3 tanesi KAFO, 2'si GRAFO, biri eklemli AFO, 17'si solid AFO kullanıyordu. KMFSS Seviye 4 olan 15 hastanın 6'sı KAFO, biri GRAFO, 8'i solid AFO kullanıyordu. KMFSS Seviye 5 olan 7 hastanın 3'ü KAFO, 4'ü solid AFO kullanıyordu (Tablo 6).

Hastaların \%20'si (n=12) yürüteç, \%3,3'ü $(n=2)$ tripod, \%5'i $(n=3)$ tetrapod, \%5'i $(n=3)$ tekerlekli sandalye kullanıyordu.

Tablo 2. Serebral palsi tipleri

\begin{tabular}{lll}
\hline Tip & Hasta Sayısı & Yüzde \\
\hline Spastik & 58 & 96,7 \\
Tetraplejik & 22 & 36,7 \\
Diplejik & 22 & 36,7 \\
Hemiplejik & 12 & 20 \\
Monoplejik & 2 & 3,3 \\
Diskinetik & 2 & 3,3 \\
\hline
\end{tabular}


Tablo 3. Hastaların fonksiyonel seviyelerinin dağılımı.

\begin{tabular}{ccc}
\hline KMFSS & Hasta Sayısı & Yüzde \\
\hline Seviye 1 & 7 & 11,7 \\
Seviye 2 & 10 & 16,7 \\
Seviye 3 & 21 & 35 \\
Seviye 4 & 15 & 25 \\
Seviye 5 & 7 & 11,7 \\
\hline
\end{tabular}

Tablo 4. Kullanılan ortezlerin dağılımı

\begin{tabular}{lcc}
\hline & Hasta Sayısı & Yüzde \\
\hline Solid AFO & 41 & 68,3 \\
Eklemli AFO & 1 & 1,7 \\
GRAFO & 6 & 10 \\
KAFO & 12 & 20 \\
\hline
\end{tabular}

AFO: Ayak-ayak bileği ortezi, GRAFO: Yer reaksiyonlu ayak-ayakbileği ortezi, KAFO: Diz-ayakbileği-ayak ortezi

Tablo 5. Serebral Palsi tipine göre ortez kullanımı

\begin{tabular}{lcccc}
\hline & $\begin{array}{c}\text { Solid AFO } \\
\text { (n) }\end{array}$ & $\begin{array}{c}\text { Eklemli AFO } \\
(\mathrm{n})\end{array}$ & $\begin{array}{c}\text { GRAFO } \\
(\mathrm{n})\end{array}$ & 3 \\
\hline Diplejik & 17 & 1 & 1 & 1 \\
Tetraplejik & 11 & - & 2 & 9 \\
Hemiplejik & 16 & - & - & 2 \\
Monoplejik & 2 & - & - & - \\
Diskinetik & 2 & - & - & - \\
\hline
\end{tabular}

AFO: Ayak-ayak bileği ortezi, GRAFO: Yer reaksiyonlu ayak-ayakbileği ortezi, KAFO: Diz-ayakbileği-ayak ortezi

Tablo 6. KMFSS seviyesine göre ortez kullanımı

\begin{tabular}{ccccc}
\hline KMFSS & $\begin{array}{c}\text { Solid AFO } \\
(\mathrm{n})\end{array}$ & $\begin{array}{c}\text { Eklemli AFO } \\
(\mathrm{n})\end{array}$ & $\begin{array}{c}\text { GRAFO } \\
(\mathrm{n})\end{array}$ & $\begin{array}{c}\text { KAFO } \\
(\mathrm{n})\end{array}$ \\
\hline Seviye 1 & 7 & - & - & - \\
Seviye2 & 7 & - & 3 & - \\
Seviye 3 & 17 & 1 & 2 & 6 \\
Seviye 4 & 8 & - & 1 & 3 \\
Seviye 5 & 4 & - & - & 3 \\
\hline
\end{tabular}

KMFSS: Kaba Motor Fonksiyon Sınıflandırma Sistemi, AFO: Ayak-ayak bileği ortezi, GRAFO: Yer reaksiyonlu ayak-ayakbileği ortezi KAFO: Diz-ayakbileği-ayak ortezi

\section{Tartışma}

Çalışmamızda SP'li çocuklarda sırasıyla en sık kullanılan ortezlerin solid AFO, KAFO, GRAFO ve eklemli AFO olduğunu saptadık. Diplejik ve hemiplejik hastalarımızda ortez çeşitlerinin kullanımı benzer olup, solid AFO en sık kullanılan ortezdi.

SP'de genellikle spastik kalça fleksör ve adduktor kaslarında, diz ve ayak bileği fleksör kaslarında spastisite vardır. Gastroknemius kasının ve invertörlerin aşırı spastisitesinden dolayı ayaklarda ekin deformitesi, pes varus ve bazen de pes valgus görülebilir. Bu kasların etkilediği eklemler olan subtalar eklem ve ayak bileği eklemi ayakta duruş pozisyonunda düzeltilmezse, multi-segmental bir zincir olan insan vücudu, diz, kalça ve gövde gibi büyük eklemlerin farklı düzlemsel hareketlerinin açısal değişikleriyle cevap verir. Bu açısal değişikliklerin artmasının önlenmesi ve kontrol altına alınması için ayağa yapılan ortez uygulamalarının faydalı olduğu bulunmuştur $[12,13]$. 
Öneş ve ark. [14] çalışmalarında SP'li hastalarda en sık AFO $(\% 35,4)$ ve KAFO $(\% 12,9)$ kullanımı olduğunu belirtmişlerdir. Özel ve ark. [15] ise çalışmalarında KMFSS düzeylerine göre, ayak bileği ortezinin (AFO) kullanımı en yüksek Seviye 2'de $(\% 71,4)$ ve Seviye 3'de $(\% 43,6)$ olduğunu saptamışlardır. SP'li çocuklarda ortez kullanımını incelediğimiz çalışmamızda, en sık kullanılan ortezin solid AFO olduğunu, daha sonra sırasıyla KAFO, GRAFO ve eklemli AFO'nun kullanıldığı saptandı.

Diplejik SP'de, alt ekstremiteler üst ekstremiteden daha fazla etkilenir. En yaygın SP formudur ve SP popülasyonunun yaklaşık \%32'si diplejikdir. Bu formda en sık görülen yürüyüş problemleri; bükük diz yürüyüşü, makaslama yürüyüşü, sıçramalı diz yürüyüşü, tutuk diz yürüyüşüdür [16]. Spastik diplejiklerde, pronasyon ayağı en sık görülen transvers plan deformitesidir. Aşırı pronasyon ya da valgus deformitesi ayağın itici gücünü ve dizde ekstansiyon momentini azaltır, adım uzunluğunu kısaltır, destek fazında ayağın stabilitesini azaltır ve enerji tüketimi artar. Hastalarda tüm bu patolojileri düzeltmek için ortotik cihaz kullanırlar [6]. Çalışmamızda 22 diplejik hastanın 17'si solid AFO, biri eklemli AFO, üçü GRAFO ve bir tanesinin KAFO kullandığı saptandı.

Hemiplejik SP'de, vücudun üst ve alt ekstremiteleri etkilenir. Fonksiyonel prognoz diğer formlardan daha iyi olup hemiplejik SP'li çocukların yürüme potansiyeli yüksektir. Bununla birlikte, ekin deformitesi en yaygın yürüme problemidir [17]. Hemiplejik formda varus ya da supinasyon ayağı sık görülür. Aşırı supinasyon parmak kalkışındaki itmeyi engeller ve yürümenin etkinliğini bozar. Ayak ortezleri ayağın anormal pronasyon ve supinasyon hareketlerini önlemek için kullanılır [6]. Çalışmamızda 20 hemiplejik SP'nin 2'si KAFO, 2'si GRAFO, 16'sı solid AFO kullanıyordu. Hem diplejik hem de hemiplejik hastalarımızda ortez çeşitlerinin kullanımı benzer olup, solid AFO en sık kullanılan ortezdi.

Ekin deformitesi, hem diplejik SP hem de hemiplejik SP'de sık görülür [17]. Ayak bileği plantar fleksiyonunu sınırlayan ve spastik kaslara pasif germe sağlayan ayak bileği ortezi (AFO), ekin deformitelerinin ilerlemesini önlemek için etkili bir konservatif tedavi olarak kabul edilir ancak optimum tedavi için diğer tedavi stratejileri (soğuk uygulama, germe egzersizleri, medikal tedaviler ve diğerleri) ile birlikte uygulanmalıdır $[18,19]$.

SP'li çocuklarda ortez kullanımının yürüyüş üzerindeki etkilerini araştıran birçok çalışma mevcuttur. Balaban ve ark. [3] hemiplejik SP'li çocuklarla yaptıkları çalışmalarında AFO uygulaması ve çıplak ayak durumunu karşılaştırmışlar ve AFO grubunda yürüme hızının, adım uzunluğunun ve tek destek süresinin arttığını bildirmişlerdir. AFO'lar ile çift destek süresi anlamlı olarak azaldığını ancak kadansta değişiklik olmadığını saptamışlardır. Ayak bileği dorsifleksiyonunda, ilk temasta, duruş ortası ve salınım ortasında anlamlı bir artış göstermişlerdir. İlk temasta diz fleksiyonun azaldığını ve AFO ile yürüyüş sırasında oksijen tüketimi önemli ölçüde azalma olduğunu belirtmişlerdir.

Öztürk ve ark. [17] KMFSS Seviye 1 ve Seviye 2 olan 30 SP'li hasta ile yaptıkları ve AFO'nun postüral denge ve fonksiyonel performans üzerine etkinliğini değerlendirdikleri çalışmalarında AFO'nun postüral kontrol, fonksiyonel performans ve fizyolojik tüketim indeksinde olumlu etkileri olduğunu göstermişlerdir.

White ve ark. [20] 115 SP'li çocukta farklı tip AFO kullanımının yürüme üzerine etkinliğini araştırmışlar, hem diplejik hem de hemiplejik SP'li çocukları kapsayan çalışmalarında, iki farklı tip solid AFO ile iki farklı tip eklemli AFO kullanmışlardır. Çocukların hepsinde farklı tipde AFO kullanımı ile yürüme hızında, adım uzunluğunda ve tek destek fazında benzer artış bulmuşlardır. Adım uzunluğundaki artışın; AFO'ların ayak bileği stabilitesini artırması ya da ayakucunda oluşturduğu ağırlık etkisi ile sarkaç etkisi yaratması sonucu olabileceği düşünülmüştür.

Tüm AFO'ların ayak bileği hareket açıklığına, yürümenin kinematik ve kinetiklerine, mobilite ile ilişkili fonksiyonel aktivitelere pozitif etkisi vardır. En sık reçete edilen AFO'lar; geleneksel solid AFO, eklemli AFO, posterior yaprak yay AFO ve yer reaksiyon AFO dur [21]. Radtka ve ark. [22] da benzer bir çalışmada, spastik diplejik SP'li çocuklarda solid ve eklemli AFO'ların yürüme üzerine etkilerini araştırmışlardır. Bu çalışmada da her iki tip AFO ile yapılan yürüme analizi sonuçlarına göre adım uzunluğunun arttığı, ilk 
temas sırasında anormal ayak bileği plantar fleksiyonunun azaldığı ve basma fazı sonunda plantar fleksiyon momentlerinin normalleştiğini bildirmişlerdir. Eklemli AFO kullanımı ile artmış ayak bileği plantar fleksiyonu momentinin bildirildiği ve terminal duruşta ayak bileği güç üretiminin azaldığı bildirilmiştir [22]. Ayrıca eklemli AFO'lu diplejik SP hastalarında durma ve salınım boyunca diz hareketinde bir değişiklik olmadığı bildirilmiştir [22, 23]. Başka bir çalışmada ayak bileği fonksiyonunu analiz ederken, hareketi en kısıtlayıcı tasarım olan solid AFO'nun, ayak bileği fonksiyonunu en fazla normalleştirme eğiliminde olduğu bildirilmiştir. Bu bulgu, diplejik SP'li birçok hasta için, ayak bileği kinematiği açısından daha uyumlu bir AFO tasarlamak adına ayak bileğinin hareket etmesine izin vermek yerine, tek bir nötr açı ile sınırlandırmak suretiyle daha iyi normalleştirilebileceğini göstermektedir [24]. Bizim çalışmamızda en fazla kullanılan ortez solid AFO idi, eklemli AFO kullanımı ise oldukça düşük saptandı.

Danino ve ark. [2] diplejik ve hemiplejik KMFSS Seviye 1-3 olan 97 SP'li hasta ile yaptıkları çalışmada AFO'ların hem diplejik hem de hemiplejik hastalarda yürüme hızını, basamak uzunluğunu ve adım uzunluğunu anlamlı derecede artırdığını göstermişlerdir. AFO hemiplejik hastalarda kadansı azaltmakta, ancak diplejik hastalarda etkilememektedir.

Ortez gibi yürümeye yardımcı cihazların da SP'li hastalarda yürüme fonksiyonunda ve sosyal yaşama katılımda iyileşmeler sağlanması, kontraktür oluşumu ve kemik deformitelerinin önlenmesi amacıyla kullanılması önerilmektedir [25]. Eriman ve ark. [26] çalışmalarında tekerlekli sandalye kullanımı $\% 5$, yürüteç kullanımını \%8 olarak bildirmişlerdir. Öneş ve ark. [14] ise yürümeye yardımcı cihaz kullanım oranlarını $\% 3,54$ tekerlekli sandalye, $\% 2,65$ yürüteç, $\% 0,88$ tripod olarak belirtmişlerdir. Bizim çalışmamızda hastalarımızın \%5'i tekerlekli sandalye, \%20'si walker, \%3,3'ü tripod, \%5’i tetrapod, kullanıyordu.

Çalışmamızda KMFSS Seviye 4 ve Seviye 5 olan hastaların yaklaşık yarısında KAFO kullanımı olduğunu gördük. Bu grupta yer alan çocuklar kendi kendilerine hareketleri sınırlı ve sıklıkla taşındıkları için yürüme amaçlı
AFO yerine pozisyonlamaya ve eklem hareket açıklığını korumaya yönelik KAFO kullanımının fazla olması beklenen sonuçtur.

Sonuç olarak SP'li hastaların fonksiyonel durumu kötüleştikçe kullanılan ortez boyutları artmakta ve kullanım amacı yürümeye yardım yerine pozisyonlamaya yönelmektedir.

Çıkar İlişkisi: Yazar çıkar ilişkisi olmadığını beyan eder.

\section{Kaynaklar}

1. Rosenbaum P, Paneth N, Leviton A, et al. A report: the definition and classificition of cerebral palsy April 2006. Dev Med Child Neurol Suppl 2007;109:8-14

2. Danino B, Erel S, Kfir M, et al. Influence of orthosis on the foot progression angle in children with spastic cerebral palsy. Gait Posture 2015;42:518-522. doi: 10.1016/j.gaitpost.2015.08.006.

3. Balaban B, Yasar E, Dal U, Yazicioglu K, Mohur H, Kalyon TA. The effect of hinged ankle-foot orthosis on gait and energy expenditure in spastic hemiplegic cerebral palsy. Disabil Rehabil 2007;29:139-144.

4. Sankar C, Mundkur N. Cerebral palsy-definition, classification, etiology and early diagnosis. Indian J Pediatr 2005;72:865-868.

5. Aboutorabi A, Arazpour M, Ahmadi Bani M, Saeedi $\mathrm{H}$, Head JS. Efficacy of ankle foot orthoses types on walking in children with cerebral palsy: A systematic review. Ann Phys Rehabil Med 2017;60:393-402. doi: 10.1016/j.rehab.2017.05.004

6. Tıkız C. Ortezler. In: Hepgüler SA, Gökben S, ed. Serebral Palsi. İstanbul: Nobel Tıp Kitabevleri, 2017;147-169.

7. Ofluoğlu D. Orthotic management in cerebral palsy. Acta Orthop Traumatol Turc 2009;43:165-172. doi:10.3944/AOTT.2009.165

8. Dilek B, Gözde G, Yakut Y. Serebral palsili çocuklarda ayak-ayak bileği ortezi kullanım süresini etkileyen faktörlerin incelenmesi: pilot çalışma. JETR 2015;2:4752.

9. Morris C. Orthotic management of cerebral palsy. Dev Med Child Neurol 2007;49:791-796. doi.org/10.1111/ j.1469-8749.2007.00791.x

10. Hagberg B, Hagberg G, Olow I. The changing panaroma of cerebral palsy in Sweden. VI. prevelance and origin during the birth year period 1983-1986. Acta Paediatrica 1993;82:387-393.

11. Palisano R, Rosenbaum P, Walter S, Russell D, Wood E, Galuppi B. Development and reliability of a system to classify gross motor function in children with cerebral palsy. Dev Med Child Neurol 1997;39:214-223. 
12. Scrutton D, Damiano D, Mayston M. Management of the motor disorders of children with cerebral palsy. 2nd edition. Cambridge: Cambridge University Press, 2004;9-146.

13. Blair E, Watson L. Epidemiology of cerebral palsy. Semin Fetal Neonatal Med 2006;11:117-125. doi:10.1016/j.siny.2005.10.010

14. Öneş K, Çelik B, Çağlar N, Gültekin Ö, Yılmaz E, Çetinkaya B. Serebral palsi polikliniğine müracaat eden hastaların demografik ve klinik özellikleri. Türk Fiz Tıp Rehab Derg 2008;54:13-16

15. Özel S, Çulha C, Delialioğlu SÜ, Sarı İF, Köklü K. The relationship between the Gross Motor Function Classification System and treatment modalities in children with cerebral palsy.Turk J Phys Med Rehab 2016;62:116-122. doi:10.5606/tttrd.2016.09069

16. Sanger TD, Delgado MR, Gaebler-Spira D, Hallett M, Mink JW; Task Force on Childhood Motor Disorders. Classification and definition of disorders causing hypertonia in childhood. Pediatrics 2003;111:89-97.

17. Öztürk B, Uygur F, Yakut Y. Effect of ankle-foot orthoses on functional performance and physiological cost index in children with cerebral palsy. JETR 2015;2:86-92

18. Houltram J, Noble I, Boyd RN, Corry I, Flett P, Graham HK. Botulinum toxin type $A$ in the management of equinus in children with cerebral palsy: an evidencebased economic evaluation. Eur J Neurol 2001;8:194202.

19. Chen W, Liu X, Pu F, et al. Conservative treatment for equinus deformity in children with cerebral palsy using an adjustable splint-assisted ankle-foot orthosis. Medicine (Baltimore) 2017;96:e8186. doi: 10.1097/ MD.0000000000008186

20. White H, Jenkins J, Neace WP, Tylkowski C, Walker J. Clinically prescribed orthoses demonstrate an increase in velocity of gait in children with cerebral palsy: a retrospective study. Dev Med Child Neurol 2002;44:227-232.

21. Çulha C. Serebral Palside Ortez Kullanımı. Turkiye Klinikleri J PM\&R-Special Topics 2017;10:56-62.

22. Radtka SA, Skinner SR, Johanson ME. A comparison of gait with solid and hinged ankle-foot orthoses in children with spastic diplegic cerebral palsy. Gait Posture 2005;21:303-310. doi:10.1016/j.gaitpost.2004.03.004

23. Buckon CE, Thomas SS, Jakobson-Huston S, Moor $M$, Sussman M, Aiona M. Comparison of three anklefoot orthosis configurations for children with spastic diplegia. Dev Med Child Neurol 2004;46:590-598.

24. Ries AJ, Novacheck TF, Schwartz MH. The efficacy of ankle -foot orthoses on improv ing the gait of children with diplegic cerebral palsy: a multiple outcome analysis. PM R. 2015;7:922-929. doi:10.1016/j.pmrj.2015.03.005
25. Shevell MI, Majnemer A, Morin I. Etiologic yield of cerebral palsy: a contemporary case series. Pediatr Neurol 2003; 28:352-359.

26. Eriman EÖ, İçağasioğlu A, Demirhan E, et al. Serebral palsili 202 olgunun demografik verileri ve klinik özellikleri. Turk J Phys Med Rehab 2009;55:94-97.

Hitit Üniversitesi Girişimsel Olmayan Etik Kurul tarih/numara: 02.05.2017/2017-39 